\title{
Intimate partner violence and childhood illnesses in Cambodia: a cross-sectional study
}

\author{
Michelle Kao Nakphong ${ }^{0},{ }^{1,2}$ Ondine $S$ von Ehrenstein ${ }^{1,2,3}$
}

- Additional material is published online only. To view please visit the journal online (http://dx.doi.org/10.1136/ archdischild-2019-317663).

1 Department of Community Health Sciences, Fielding School of Public Health, University of California Los Angeles, Los Angeles, California, USA ${ }^{2}$ California Center for Population Research, University of California, Los Angeles, Los Angeles, CA, USA

${ }^{3}$ Department of Epidemiology, Fielding School of Public Health, University of California Los Angeles, Los Angeles, California, USA

\section{Correspondence to}

Michelle Kao Nakphong, Department of Community Health Sciences, Fielding School of Public Health, University of California Los Angeles, Los Angeles, CA 90095, USA; hmkao@ucla.edu

Received 9 June 2019 Revised 31 October 2019 Accepted 1 November 2019 Published Online First 16 January 2020

\section{ABSTRACT}

Background Around a quarter of Cambodian women reported being victim to intimate partner violence (IPV) from their current partner. Children's exposure to familial IPV impacts psychosocial well-being and emerging research indicates associations with physical health. Objective Investigate associations between maternal experience of IPV and common childhood illnesses in Cambodia.

Design, setting, participants Analysis of the Cambodia Demographic and Health Survey (2000, 2005, 2014) using logistic regression, including 5025 children under 5 years of age whose mothers responded to questions about experience of emotional, physical and sexual violence by current partner.

Main outcome measures Report of diarrhoea, acute respiratory infection (ARI) or fever, respectively, in children in the two weeks preceding the survey.

Results Children of mothers with experience of any type of IPV had estimated elevated odds of diarrhoea (adjusted $\mathrm{OR}(\mathrm{aOR})=1.65,95 \% \mathrm{Cl} 1.39$ to 1.97$)$, estimated odds of ARI $(\mathrm{aOR}=1.78,95 \% \mathrm{Cl} 1.47$ to 2.16) and estimated odds of fever $(\mathrm{aOR}=1.51,95 \% \mathrm{Cl}$ 1.31 to 1.76 ) compared with children of mothers without reported IPV experience. Exposure to any form of IPV corresponded to an estimated 2.65 times higher odds ( $95 \% \mathrm{Cl} 2.01$ to 3.51$)$ for reporting having both diarrhoea and ARI.

Conclusions Our findings support the notion that children's susceptibility to diarrhoea, ARI and fever may be affected by mothers' experience of IPV, including emotional violence. Maternal and child health programmes should train healthcare professionals to identify domestic violence and children at risk, and link victims to appropriate health and legal services.

\section{INTRODUCTION}

Children are often the unseen victims of intimate partner violence (IPV) committed against women. As one of the most common forms of domestic violence, IPV is estimated to affect between $10 \%$ and $69 \%$ of women globally, ${ }^{1}$ but enumerations of children impacted are rare and likely underestimated. ${ }^{2}$ Current literature regarding the impact of IPV on children favours using a broader definition of 'exposure' over 'witnessing', acknowledging that both a child's direct witness as well as awareness of violence may be traumatic. ${ }^{3}$ Exposure to physical, sexual or emotional abuse against a child's parents, caregivers or family members committed by an intimate partner, is recognised as a form of child maltreatment which may negatively impact psychological, social and emotional development and

\section{What is already known on this topic?}

- Children's physical health is affected by exposure to intimate partner violence (IPV), documented in studies investigating conditions such as asthma, or chronic malnutrition.

- Increased odds of children's diarrhoea and acute respiratory infection (ARI) associated with exposure to physical and sexual IPV have been found in African and South Asian studies.

\section{What this study adds?}

- This is the first study (to our knowledge) in Cambodia associating children's physical health with maternal experience of IPV.

- Maternal report of experience of emotional violence alone was positively associated with children's diarrhoea, ARI and fever.

- Maternal experience of any form of IPV was associated with increased odds of a child having both diarrhoea and ARI.

well-being. ${ }^{4}$ Evolving research further indicates that maternal IPV victimisation contributes to adverse physical health outcomes in children. ${ }^{5}$

Investigation of IPV exposure within different country contexts have provided insight into sociodemographic risk patterns related to IPV. ${ }^{6}$ According to the Cambodia Demographic and Health Survey (CDHS) reports, $28.7 \%$ of ever-married women in 2014 report their current or last partner has committed emotional, physical or sexual violence against them. ${ }^{7}$ In Cambodia, it has been suggested that a history of collective violence and economic growth coupled with urban migration may be linked to violence against women. ${ }^{8}$ Heightened awareness of gender-based violence has led to increased political commitment to address IPV. Between 1999 and 2014, Cambodia developed a policy framework to address violence against women including the Convention of the Elimination of All Forms of Violence Against Women (1999) and the National Action Plan to Prevent Violence Against Women (2013), among others. ${ }^{89}$ Yet, despite the growing women's rights political discourse, estimated prevalence of IPV against women has remained high over the last two decades, leading some to cite lack of institutional capacity and persistent social norms as factors. ${ }^{910}$

Less research has focused on IPV's impacts on children's physical health. ${ }^{11}$ Some studies of 
exposure to parental IPV have focused on critical perinatal and birth periods, revealing associations with adverse birth and neonatal health outcomes as well as delayed development. ${ }^{12} 13$ Fewer studies have addressed impacts beyond infancy, but some studies indicate that stunting, wasting or underweight physical status ${ }^{14}{ }^{15}$ under 5 years mortality ${ }^{16}{ }^{17}$ and asthma ${ }^{18}$ are associated with maternal IPV victimisation. Several studies in lowincome and middle-income countries have found associations with diarrhoea and acute respiratory infection (ARI). ${ }^{19-23}$ These illnesses, which remain leading causes of childhood mortality in low-income and low-middle-income countries, account for roughly a quarter of childhood deaths under 5 years. ${ }^{24}$ An exploration of IPV exposure on children's physical health in Cambodia will complement extant research of IPV's impact on children's psychological and behavioural well-being.

We hypothesise that maternal IPV victimisation in Cambodia is associated with early childhood illness assessed as diarrhoea, ARI and fever. From an Interactive Biopsychosocial Model perspective, ${ }^{25} 26$ which highlights the interrelated biophysical, psychocognitive and social processes in health and illness, we posit that all recorded types of IPV may be associated with children's increased risk for illness. This study aims to examine associations of maternal report of IPV victimisation, considering types of violence, with common childhood illnesses-diarrhoea, $\mathrm{ARI}$ and fever.

\section{METHODS}

\section{Study design}

We combined data collected in years 2000, 2005 and 2014 from the national, population-based CDHS. ${ }^{727}$ In the CDHS, the domestic violence module was administered to a randomly selected subgroup of 7685 currently or formerly married women between 15 years and 49 years of age. The module was administered only if privacy was ensured; privacy was not possible for 71 women, comprising $0.9 \%$ of the sample.

In total, the three CDHS assessments included child morbidity data of 5025 children under 5 years born to 3864 women who completed the domestic violence module, and who lived with both mother and mother's partner at the time of interview. We excluded children whose mothers reported not knowing or being unclear on symptoms, resulting in a final sample of 4940 children (see online supplementary 1).

\section{Data collection}

\section{Violence assessment}

The Demographic and Health Survey (DHS) Programme domestic violence module employs a modified Conflict Tactics Scale approach to measure IPV. ${ }^{59}$ Used across multiple countries, this module has standardised methodology and strict guidelines to maximise validity and reliability in data collection. The module has evolved to increase validity in keeping with current IPV research (questions and modifications detailed in online supplementary 2). In Cambodia, DHS estimates have been corroborated by the Household Survey of Domestic Violence in Cambodia. ${ }^{5}$ Maternal experience of IPV by current partner was assessed by self-report and classified by type. Children of mothers reporting IPV victimisation were compared with children whose mothers reported no experience of IPV. We considered IPV types related to at least 25 children with illness, and exposure groups were defined accordingly: emotional violence only; physical violence only; both emotional and physical violence; and experience of emotional, physical and sexual violence together. Because of small sample sizes, we did not consider experience of sexual violence only, having both emotional and sexual violence, and both physical and sexual violence.

\section{Child health outcomes}

Mothers reported children's diarrhoea, cough, cough accompanied by short, rapid breathing (symptoms compatible with ARI) and fever in the previous 2 weeks. Each outcome was dichotomised, using those without reported symptoms as reference. Specifically for ARI, the reference were those with no ARI and no cough. We also considered report of having both, diarrhoea and ARI in the previous 2 weeks.

\section{Sociodemographic household and maternal variables}

Household information included urban or rural residence, wealth quintile indicator, type of sanitation facility, drinking water source and cooking fuel. Maternal characteristics included age, education, smoking status and parity.

\section{Ethics approval}

This study involved secondary analysis of publicly available, deidentified data sets from the DHS. To ensure privacy and confidentiality, DHS follows strict procedures for obtaining consent and obtains an additional informed consent for the domestic violence module to protect the privacy and well-being of respondents.

\section{Analyses}

Data from the 2000, 2005 and 2014 CDHS assessment years were combined. Logistic regression was used to estimate crude and adjusted ORs (aORs) and 95\% CIs. We selected covariates based on prior literature about associations with IPV or the considered outcomes. All multivariable models adjusted for child's age, residence (urban/rural), mother's age at child's birth, maternal education, wealth indicator and maternal smoking status. ${ }^{2}$ Standard errors were adjusted using a Huber-White sandwich estimator to account for clustering by mother. Models for specific outcomes included additional a priori selected relevant variables: models for diarrhoea also adjusted for source of drinking water (ie, improved vs non-improved, based on WHO definitions) and household sanitation facility (ie, improved, not shared vs non-improved or shared). The models for ARI were also adjusted for cooking fuel (electricity, liquified propane gas, natural gas, biogas, other and no cooking vs charcoal, firewood, kerosene, agricultural crops and dung). In sensitivity analyses, we considered additional variables added to the model: possession of health card as a measure of healthcare utilisation, birth order and parity. We excluded these from final models because of collinearity or negligible effect on point estimates and standard errors (less than $5 \%$ change). ${ }^{30}$ Frequencies of medical treatment received were examined stratified by maternal IPV experience. We conducted a complete case analysis, excluding 85 observations with missing data. Distributions of outcomes and covariates among observations with missing data were similar to those with complete data and were considered missing at random. Stata/SE V.15.1 was used for all analyses.

\section{RESULTS}

Among all ever-married women who responded to the IPV assessment, $25 \%$ in the 2000 survey reported ever being victim to IPV, compared with $22.3 \%$ in 2005 and $28.7 \%$ in 2014 . Children of women who experienced IPV tended to be of a slightly later birth order with a greater percentage of children who were the third birth or later (table 1). Mothers victimised by IPV were 
Table 1 Social and demographic characteristics of children whose mothers responded to the questionnaire module on experience of IPV in the 2000, 2005, 2014 CDHS

\begin{tabular}{|c|c|c|}
\hline & $\begin{array}{l}\text { Children whose } \\
\text { mothers have } \\
\text { ever experienced } \\
\text { IPV } \\
\mathrm{n}=1230\end{array}$ & $\begin{array}{l}\text { Children whose } \\
\text { mothers have } \\
\text { never experienced } \\
\text { IPV } \\
\mathrm{n}=3795\end{array}$ \\
\hline \multicolumn{3}{|c|}{ Mother's experience of IPV by type } \\
\hline Emotional only & $411(33.4 \%)$ & --- \\
\hline Physical only & $216(17.6 \%)$ & --- \\
\hline Sexual only & $30(2.4 \%)$ & --- \\
\hline Physical and sexual & $15(1.2 \%)$ & --- \\
\hline Emotional and physical & $418(34.0 \%)$ & --- \\
\hline Emotional and sexual & $35(2.9 \%)$ & --- \\
\hline Emotional, physical and sexual & $105(8.5 \%)$ & --- \\
\hline \multicolumn{3}{|l|}{ Sex of child } \\
\hline Male & $629(51.1 \%)$ & $1911(50.4 \%)$ \\
\hline Female & $601(48.9 \%)$ & $1884(49.6 \%)$ \\
\hline \multicolumn{3}{|l|}{ Age of child } \\
\hline Under 1 year & $239(19.4 \%)$ & $799(22.0 \%)$ \\
\hline $12-23$ months & $226(18.4 \%)$ & $740(19.5 \%)$ \\
\hline $24-35$ months & $237(19.3 \%)$ & $745(19.6 \%)$ \\
\hline $36-47$ months & $276(22.4 \%)$ & $750(19.8 \%)$ \\
\hline $48-59$ months & $252(20.5 \%)$ & $761(20.1 \%)$ \\
\hline \multicolumn{3}{|l|}{ Birth order number of child } \\
\hline First or second & $497(40.4 \%)$ & $1982(52.2 \%)$ \\
\hline Third or fourth & $396(32.2 \%)$ & $1080(28.5 \%)$ \\
\hline Fifth or higher & $337(27.4 \%)$ & $733(19.3 \%)$ \\
\hline \multicolumn{3}{|l|}{ Child has health card } \\
\hline Yes & $1077(87.6 \%)$ & $3380(89.1 \%)$ \\
\hline No & $152(12.4 \%)$ & $412(10.9 \%)$ \\
\hline Missing data & $1(0.08 \%)$ & $3(0.1 \%)$ \\
\hline \multicolumn{3}{|l|}{ Mother's age at birth, years } \\
\hline$<15$ & $0(0 \%)$ & $1(0.0 \%)$ \\
\hline $15-19$ & $89(7.2 \%)$ & $397(10.5 \%)$ \\
\hline $20-24$ & $300(24.4 \%)$ & $1033(27.2 \%)$ \\
\hline $25-29$ & $359(29.2 \%)$ & $1085(28.6 \%)$ \\
\hline $30-34$ & $273(22.2 \%)$ & $741(19.5 \%)$ \\
\hline $35-39$ & $153(12.4 \%)$ & $391(10.3 \%)$ \\
\hline $40-44$ & $52(4.2 \%)$ & $132(3.5 \%)$ \\
\hline $45-49$ & $4(0.3 \%)$ & $15(0.4 \%)$ \\
\hline \multicolumn{3}{|l|}{ Mother's education } \\
\hline No education & $375(30.5 \%)$ & $907(23.9 \%)$ \\
\hline Primary & $692(56.3 \%)$ & $1966(51.8 \%)$ \\
\hline Secondary & $158(12.9 \%)$ & $869(22.9 \%)$ \\
\hline Higher & $5(0.4 \%)$ & $53(1.4 \%)$ \\
\hline \multicolumn{3}{|l|}{ Smoking status } \\
\hline Smoker & $214(17.4 \%)$ & $403(10.6 \%)$ \\
\hline Non-smoker & $1016(82.6 \%)$ & $3392(89.4 \%)$ \\
\hline \multicolumn{3}{|l|}{ Type of residence } \\
\hline Urban & $217(17.6 \%)$ & $738(19.5 \%)$ \\
\hline Rural & $1013(82.4 \%)$ & $3057(80.6 \%)$ \\
\hline \multicolumn{3}{|l|}{ Wealth Index } \\
\hline Poorest & $392(31.9 \%)$ & $967(25.5 \%)$ \\
\hline Poorer & $312(25.4 \%)$ & $840(22.1 \%)$ \\
\hline Middle & $201(16.3 \%)$ & $716(18.9 \%)$ \\
\hline Richer & $186(15.1 \%)$ & $604(15.9 \%)$ \\
\hline Richest & $139(11.3 \%)$ & $668(17.6 \%)$ \\
\hline
\end{tabular}

Table 1 Continued

\begin{tabular}{|c|c|c|}
\hline & $\begin{array}{l}\text { Children whose } \\
\text { mothers have } \\
\text { ever experienced } \\
\text { IPV } \\
\mathrm{n}=1230\end{array}$ & $\begin{array}{l}\text { Children whose } \\
\text { mothers have } \\
\text { never experienced } \\
\text { IPV } \\
\mathrm{n}=3795\end{array}$ \\
\hline \multicolumn{3}{|l|}{$\begin{array}{l}\text { Drinking water source (during dry } \\
\text { season) }\end{array}$} \\
\hline Improved & $493(40.1 \%)$ & $1772(46.7 \%)$ \\
\hline Non-improved & $728(59.2 \%)$ & 2006 (52.9\%) \\
\hline Missing & $9(0.7 \%)$ & $17(0.5 \%)$ \\
\hline \multicolumn{3}{|l|}{ Household sanitation facility } \\
\hline Improved, not shared & $49(4.0 \%)$ & $224(5.9 \%)$ \\
\hline Non-improved or shared & $1175(95.5 \%)$ & $3555(93.7 \%)$ \\
\hline Missing & $6(0.5 \%)$ & $16(0.4 \%)$ \\
\hline \multicolumn{3}{|l|}{ Cooking fuel } \\
\hline $\begin{array}{l}\text { Clean (electricity, LPG, NG, biogas, no } \\
\text { cooking within the home) }\end{array}$ & $66(5.4 \%)$ & $381(10.0 \%)$ \\
\hline $\begin{array}{l}\text { Dirty (coal, charcoal, wood/straw/ } \\
\text { shrubs, agricultural crops, dung, } \\
\text { kerosene) }\end{array}$ & $1157(94.1 \%)$ & 3396 (89.5\%) \\
\hline Missing & $7(0.6 \%)$ & $18(0.5 \%)$ \\
\hline
\end{tabular}

CDHS, Cambodia Demographic and Health Survey; IPV, intimate partner violence.

slightly older at time of birth, had lower educational attainment, and more were smokers. Children exposed to IPV lived in households with slightly lower wealth index scores, more had non-improved drinking water sources and fewer used cleaner cooking fuels.

Fever was most frequently reported (32.7\%), followed by cough (27.3\%), ARI (15.2\%) and diarrhoea (17.2\%) (see online supplementary 3). Having both diarrhoea and ARI was reported by $5.7 \%$ of the total sample, constituting $13.9 \%$ of children with any illness (see online supplementary 4 ).

All types of IPV considered were associated with an increased odds of at least one physical illness assessed (table 2). Maternal report of any IPV was associated with increased odds of a child having an illness in the 2 weeks prior to the assessment (aOR $=1.65,95 \% \mathrm{CI} 1.43$ to 1.91$)$. By type of violence, maternal report of emotional violence only related to an elevated odds of a child's illness (aOR $=1.89,95 \%$ CI 1.50 to 2.37$)$. In sensitivity analyses restricted to first-born children, maternal victimisation related to an OR of 1.99 (95\% CI 1.47 to 2.68 ) of a child having at least one illness (see online supplementary 5).

Mothers' experience of IPV related to children's elevated odds of diarrhoea ( $\mathrm{aOR}=1.66,95 \% \mathrm{CI} 1.40$ to 1.98$)$, elevated odds of ARI (aOR $=1.78,95 \% \mathrm{CI} 1.47$ to 2.16$)$ and elevated odds of fever $(\mathrm{aOR}=1.52,95 \% \mathrm{CI} 1.31$ to 1.76 ) (see online supplementary 6). ARI was positively associated with all IPV types considered (figure 1). Overall, experience of any type of IPV, emotional violence only, emotional and physical violence, and combined emotional, physical and sexual violence were associated with elevated odds for any symptom of diarrhoea, ARI and fever. In particular, experience of emotional violence only was associated with ORs ranging from 1.76 (95\% CI 1.40 to 2.21$)$ for fever to 2.13 (95\% CI 1.64 to 2.76 ) for diarrhoea. Physical violence only was associated with estimated odds for ARI and fever while there was no association with diarrhoea suggested.

Exposure to any maternal victimisation related to 2.6 fold elevated odds of having both diarrhoea and ARI $(95 \%$ CI 2.0 to 3.5) (table 3). Estimated ORs for emotional violence alone suggested similar positive associations. Sensitivity analyses 
Table 2 Maternal experience of IPV and child morbidity by type of violence and sex of child

\begin{tabular}{|c|c|c|c|c|c|c|}
\hline \multirow[b]{3}{*}{ Experience of IPV by type } & \multicolumn{6}{|l|}{ Child morbidity* } \\
\hline & \multicolumn{2}{|l|}{ Sexes combined } & \multicolumn{2}{|l|}{ Boys } & \multicolumn{2}{|l|}{ Girls } \\
\hline & $\begin{array}{l}\text { N IPV cases/n IPV } \\
\text { non-cases }\end{array}$ & $\begin{array}{l}\text { aORt } \\
(95 \% \mathrm{Cl})\end{array}$ & $\begin{array}{l}\text { N IPV cases/n IPV } \\
\text { non-cases }\end{array}$ & $\begin{array}{l}\text { aORt } \\
(95 \% \mathrm{Cl})\end{array}$ & $\begin{array}{l}\text { N IPV cases/n IPV } \\
\text { non-cases }\end{array}$ & $\begin{array}{l}\text { aORt } \\
(95 \% \mathrm{Cl})\end{array}$ \\
\hline Experience of any type of IPV & $600 / 604$ & $1.65(1.43$ to 1.91$)$ & $325 / 290$ & $1.76(1.45$ to 2.15$)$ & $275 / 314$ & $1.58(1.29$ to 1.93$)$ \\
\hline Emotional only & $211 / 190$ & $1.89(1.50$ to 2.37$)$ & $119 / 89$ & 2.19 (1.62 to 2.95$)$ & $92 / 101$ & $1.67(1.22$ to 2.30$)$ \\
\hline Physical only & $95 / 119$ & $1.27(0.94$ to 1.71$)$ & $52 / 68$ & $1.15(0.78$ to 1.7$)$ & $43 / 51$ & $1.39(0.90$ to 2.14$)$ \\
\hline Emotional and physical & $206 / 203$ & $1.68(1.34$ to 2.11$)$ & $106 / 94$ & 1.77 (1.29 to 2.44$)$ & $100 / 109$ & $1.62(1.19$ to 2.21$)$ \\
\hline Emotional, physical and sexual & $51 / 52$ & 1.65 (1.07 to 2.57$)$ & $29 / 21$ & 2.09 (1.16 to 3.77$)$ & $22 / 31$ & $1.43(0.78$ to 2.65$)$ \\
\hline
\end{tabular}

*Child morbidity refers to any maternal report of diarrhoea, symptoms of acute respiratory infection or fever in the 2 weeks prior to the DHS.

†Adjusted OR covariates: child's age, mother's age at birth, maternal education, wealth index, mother's smoking status, place of residence, survey year and adjusted for clustering by mother using a Huber-White sandwich estimator.

DHS, Demographic and Health Survey; IPV, intimate partner violence.

adjusting additionally for cooking fuel and sanitation in models of co-reported diarrhoea and ARI did not change our findings appreciably (data not shown).

Fewer children whose mothers reported IPV received medical treatment for diarrhoea than children whose mothers did not report IPV (32.0\% vs 39.5\%). Additionally, fewer children whose mothers reported IPV received medical treatment for fever and/or cough than children whose mothers did not report IPV (41.6\% vs $48.7 \%)$

\section{DISCUSSION}

Our study suggests adult IPV may impact children's physical health outcomes assessed as diarrhoea, ARI and fever. To our knowledge, this is the first study in Cambodia examining child morbidity associated with maternal IPV victimisation.
In this population-based study we estimated positive associations considering different kinds of IPV. Our findings support the hypothesis that maternal IPV victimisation may increase children's susceptibility to illness. These associations do not appear to be explained by differences in wealth, age or housing characteristics.

Unlike prior studies of associations with diarrhoea and ARI ${ }^{19-23}$ we examined the impacts of emotional violence and assessed associations according to clearly delineated types of IPV. Notably, our exploration of maternal experience of emotional violence alone was related to increased odds of children's diarrhoea, ARI or fever. Our estimates are comparable to those found in similar studies in South Asia, Uganda, Tanzania and Nigeria. ${ }^{19-23}$ However, these studies did not conduct analyses by specific types of violence and aside from the Tanzanian study,

\section{Associations of Intimate Partner Violence Exposure and Child Morbidity by Type of Violence}

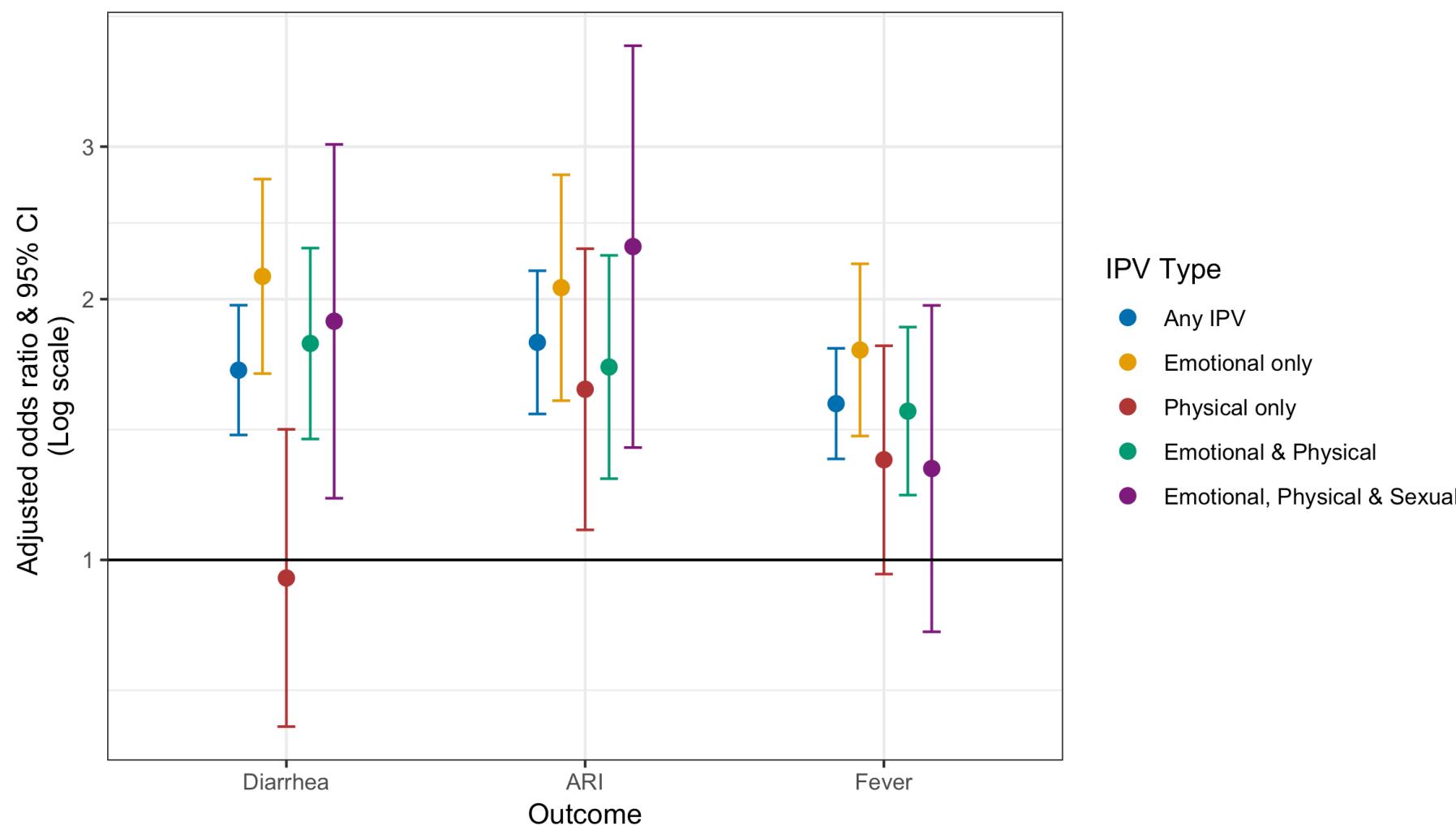

Figure 1 Associations of intimate partner violence (IPV) and child morbidity by type of violence. ARI, acute respiratory infection. 
Table 3 Maternal experience of IPV in relation to report of both child diarrhoea and ARI

\begin{tabular}{llll}
\hline & \multicolumn{2}{l}{ Report of diarrhoea and ARI } \\
\cline { 2 - 4 } Experience of IPV by type & $\begin{array}{l}\text { N IPV cases/n IPV } \\
\text { non-cases }\end{array}$ & $\begin{array}{l}\text { Crude OR } \\
(95 \% \mathrm{CI})\end{array}$ & $\begin{array}{l}\text { aOR }^{*} \\
(95 \% \mathrm{Cl})\end{array}$ \\
\hline Experience of any type of IPV & $114 / 604$ & $2.60(2.01$ to 3.35) & $2.64(1.99$ to 3.50) \\
Emotional only & $45 / 190$ & $3.26(2.27$ to 4.67$)$ & $3.64(2.40$ to 5.50) \\
Emotional and physical & $41 / 203$ & $2.78(1.92$ to 4.02) & 2.91 (1.93 to 4.41) \\
\hline
\end{tabular}

*Adjusted OR covariates: child's age, mother's age at birth, maternal education, wealth index, mother's smoking status, place of residence, survey year and adjusted for clustering by mother using a Huber-

White sandwich estimator.

$\mathrm{aOR}$, adjusted $\mathrm{OR}$; $\mathrm{ARI}$, acute respiratory infection; IPV, intimate partner violence.

these studies did not examine emotional violence. Additionally, our findings suggest that fewer ill children of mothers who report IPV receive medical treatment than children of mothers who do not report IPV.

Based on the cross-sectional survey design, we were unable to relate diarrhoea, ARI and fever directly to maternal experience of IPV. Our ability to assess causality of the associations based on the currently available data is limited. Survey measures were also self-reported and thus we cannot exclude the possibility of reporting bias, which might bias our findings if mothers who reported IPV differentially reported child health problems. However, from previous studies IPV was more likely to be under-reported, ${ }^{10}$ considering the sensitivity of the subject matter, which would likely attenuate our estimates. Modifications of questions in the domestic violence module between 2005 and 2014 may have resulted in increased prevalence estimates as questions included broader experiences of IPV, but we found no meaningful differences in estimates of association across survey years. Despite the subjective nature of symptom identification, mothers are likely able to identify common symptoms (ie, less than $0.2 \%$ of the sample reported not knowing whether a symptom was present). Importantly, we do not expect recall or misclassification of symptoms to be differential with respect to experience of IPV.

We also lacked information on other potentially important factors that might confound associations between maternal IPV victimisation and child illness and residual confounding always remains a concern. Including multiple children from mothers may have affected estimates. However, sensitivity analyses including only first-born children resulted in similar estimated ORs but with wider CIs, likely due to smaller sample size. Future research may examine the role of number of children (and pregnancies) in this association. Interviews did not include information about the type of exposure children had to IPV, for example, whether they directly observed violence or were aware of its occurrence. We lacked information about occurrence of child abuse, which often accompanies IPV, ${ }^{3}$ and may confound or mediate the associations between IPV and child illness. Furthermore, reports of IPV lacked temporal information and measures of severity which limited our ability to assess how the degree and extent of IPV related to children's illness. Lastly, we were unable to assess certain types of IPV such as sexual violence because the number of exposed cases was too small.

Consistent with the Interactive Biopsychosocial Model, ${ }^{25} 26$ these findings support the hypothesis that inter-related biological, psychological and social factors related to IPV affect children's well-being. Cambodian children exposed to violence at home are five times more likely to have depressive symptoms and Cambodian male perpetrators are 1.5-3 times more likely than non-perpetrators to have witnessed abuse against their mothers, indicating cyclic patterns of victimisation and abuse. ${ }^{631}$ However, the links between IPV and physical health have been less clear; extant literature regarding the physical impact of maternal IPV on children's health have proposed both sociobehavioural as well as biological mechanisms as possible pathways.

One body of literature supports a sociobehavioural pathway, suggesting that IPV alters caregiving behaviour, subsequently affecting children's physical health. Using longitudinal data, English et al concluded that caregiver depression, family health and competence mediated the impact of IPV on children's health. ${ }^{32}$ It has also been proposed that controlling behaviour associated with IPV undercuts women's decision-making or interferes with women's ability to use healthcare and access health-related knowledge for themselves or their children. ${ }^{18} 3334$

A growing body of evidence suggests that biological mechanisms also mediate the relationship between IPV exposure and children's health. The cumulative effects of chronically elevated stress responses during critical and sensitive periods has known psychological and developmental effects. ${ }^{35} 36$ Recent studies linking IPV exposure and childhood asthma implicate physiological stress responses as a critical risk factor for atopy, increasing children's vulnerability to pathogens, toxics and subsequent illness. $^{37} 38$

Future research may explore these potential mediators and mechanisms responsible for the associations between maternal IPV victimisation and children's physical health, especially in low-income and middle-income countries. Studies may consider including social indicators, such as culturally specific caregiving and child maltreatment behaviours, or collect biomarker data. Given Cambodia's specific cultural and social factors, generalisability to other contexts is potentially limited. However, our estimates are comparable to other similar studies, suggesting that this relationship may exist across cultures, meriting further investigation of these associations in other populations.

\section{CONCLUSIONS}

Our findings support the notion that adult IPV affects children's well-being. Estimated prevalence of IPV has remained relatively unchanged over the past two decades. ${ }^{10}$ Reducing maternal IPV victimisation could be an important strategy to promote child health in Cambodia. Maternal and child health programmes should train healthcare professionals to identify domestic violence and children at risk, and link victims to appropriate health and legal services. Communication from the health sector can also raise public awareness about the effects of IPV and challenge social norms and attitudes that perpetuate IPV.

Children's health is inextricably linked to women's health and violence against women affects children. Cambodia's current rate of development and growing women's rights discourse yields potential points of intervention. National domestic violence laws in Cambodia have been in effect since 2005, but this legal reform has failed to produce equity and justice for women. ${ }^{39} 40$ Awareness of the impact of IPV exposure on children may support efforts to reduce IPV prevalence, improve victim protection and increase domestic violence law enforcement. ${ }^{40}$ Given the multifaceted nature of IPV, development of new approaches and multisector collaboration may be needed to promote the health of women and children.

Acknowledgements The authors thank Dyna Khuon for providing insights into Cambodia's institutional and cultural contexts.

Contributors MKN conceived of the study, conducted analyses and was the primary author. OvE supported the development of the work, contributed to the analytic approach, data interpretation and manuscript preparation. 
Funding The authors have not declared a specific grant for this research from any funding agency in the public, commercial or not-for-profit sectors.

Competing interests None declared.

Patient consent for publication Not required.

Ethics approval Questions and procedures were approved by the ICF International IRB to ensure compliance with US regulations for the protection of human subjects (45-CFR-46).

Provenance and peer review Not commissioned; externally peer reviewed.

Data availability statement Data are available in a public, open access repository.

\section{ORCID iD}

Michelle Kao Nakphong http://orcid.org/0000-0003-2632-8007

\section{REFERENCES}

1 Heise L, Ellsberg M, Gottemoeller M. Ending violence against women. Baltimore, MD: Johns Hopkins University School of Public Health, Center for Communications Programs, 1999. (Series L). Report No.: 11.

2 Wathen CN, Macmillan HL. Children's exposure to intimate partner violence: impacts and interventions. Paediatr Child Health 2013;18:419-22.

3 Holt S, Buckley $\mathrm{H}$, Whelan $\mathrm{S}$. The impact of exposure to domestic violence on children and young people: a review of the literature. Child Abuse Neg/ 2008;32:797-810.

4 MacMillan HL, Wathen CN. Children's exposure to intimate partner violence. Child Adolesc Psychiatr Clin N Am 2014;23:295-308.

5 Kishor S, Johnson K. Profiling domestic violence: a Multi-country study. Calverton, MD: ORC Macro, 2004

6 Fulu E, Jewkes R, Roselli T, et al. Prevalence of and factors associated with male perpetration of intimate partner violence: findings from the un Multi-country crosssectional study on men and violence in Asia and the Pacific. Lancet Glob Health 2013:1:e187-207.

7 National Institute of Statistics, [Cambodia]. Cambodia demographic and health survey 2014. Phnom Penh, Cambodia, and Rockville, Maryland, USA: National Institute of Statistics, Directorate General for Health, and ICF International, 2015.

8 Fulu E, Miedema S. Violence against women: globalizing the integrated ecological model. Violence Against Women 2015;21:1431-55.

9 Ministry of Women's Affairs. Cambodia gender assessment: violence against women and girls. Phnom Penh, Cambodia: Ministry of Women's Affairs, 2014. Report No.: Policy Brief Chapter 7

10 Ministry of Women's Affairs, National Institute of Public Health. National Institute of Statistics [Cambodia]. Women's experience of domestic violence and other forms of violence, 2016: 78

11 Bair-Merritt MH, Blackstone M, Feudtner C. Physical health outcomes of childhood exposure to intimate partner violence: a systematic review. Pediatrics 2006;117:e278-90.

12 Asling-Monemi K, Naved RT, Persson LA. Violence against women and the risk of feta and early childhood growth impairment: a cohort study in rural Bangladesh. Arch Dis Child 2009;94:775-9.

13 Hill A, Pallitto C, McCleary-Sills J, et al. A systematic review and meta-analysis of intimate partner violence during pregnancy and selected birth outcomes. Int $\mathrm{J}$ Gynaecol Obstet 2016:133:269-76.

14 Chai J, Fink G, Kaaya S, et al. Association between intimate partner violence and poor child growth: results from 42 demographic and health surveys. Bull World Health Organ 2016:94:331-9.

15 Ziaei S, Naved RT, Ekström E-C. Women's exposure to intimate partner violence and child malnutrition: findings from demographic and health surveys in Bangladesh. Matern Child Nutr 2014;10:347-59.

16 Silverman JG, Decker MR, Cheng DM, et al. Gender-Based disparities in infant and child mortality based on maternal exposure to spousal violence. Arch Pediatr Adolesc Med 2011;165:22-7.
17 Asling-Monemi K, Peña R, Ellsberg MC, et al. Violence against women increases the risk of infant and child mortality: a case-referent study in Nicaragua. Bull World Health Organ 2003:81:10-16.

18 Wright RJ. Prenatal maternal stress and early caregiving experiences: implications for childhood asthma risk. Paediatr Perinat Epidemiol 2007;21:8-14.

19 Silverman JG, Decker MR, Gupta J, et al. Maternal experiences of intimate partner violence and child morbidity in Bangladesh: evidence from a national Bangladeshi sample. Arch Pediatr Adolesc Med 2009;163:700-5.

20 Ferdousy EZ, Matin MA. Association between intimate partner violence and child morbidity in South Asia. J Health Popul Nutr 2015;33:16.

21 Karamagi CAS, Tumwine JK, Tylleskar T, et al. Intimate partner violence and infant morbidity: evidence of an association from a population-based study in eastern Uganda in 2003. BMC Pediatr 2007;7:34.

22 Hossain MB, Udo I, Phillips JF. Association between spousal violence and the incidence of acute respiratory infection among children under five: random-effect modelling using data from Nigeria and Bangladesh. J Biosoc Sci 2019;51:534-48.

23 Bintabara D, Kibusi SM. Intimate partner violence victimization increases the risk of under-five morbidity: a stratified multilevel analysis of pooled Tanzania demographic health surveys, 2010-2016. PLoS One 2018;13:e0201814.

24 Liu L, Johnson HL, Cousens S, et al. Global, regional, and national causes of child mortality: an updated systematic analysis for 2010 with time trends since 2000. The Lancet 2012:379:2151-61.

25 Engel GL. The clinical application of the biopsychosocial model. Am J Psychiatry 1980:137:535-44

26 Lindau ST, Laumann EO, Levinson W, et al. Synthesis of scientific disciplines in pursuit of health: the interactive biopsychosocial model. Perspect Biol Med 2003;46:S74-86.

27 National Institute of Public Health, National Institute of Statistics [Cambodia], ORC Macro. Cambodia demographic and health survey 2005. Phnom Penh, Cambodia and Calverton, Maryland, USA: National Institute of Public Health, National Institute of Statistics and ORC Macro, 2006.

28 National Institute of Statistics, [Cambodia], ORC Macro. Cambodia demographic and health survey 2000. Phnom Penh, Cambodia and Calverton, Maryland, USA: National Institute of Statistics, Directorate General for Health, and ORC Macro, 2001: 269-73.

29 Straus MA, Hamby SL, Boney-McCoy S, et al. The revised conflict tactics scales (CTS2): development and preliminary psychometric data. J Fam Issues 1996;17:283-316.

30 Greenland S. Invited commentary: variable selection versus shrinkage in the control of multiple confounders. Am J Epidemiol 2008;167:523-9. discussion 530-531.

31 Ong KIC, Yi S, Tuot S, et al. What are the factors associated with depressive symptoms among orphans and vulnerable children in Cambodia? BMC Psychiatry 2015:15:178.

32 English DJ, Marshall DB, Stewart AJ. Effects of family violence on child behavior and health during early childhood. J Fam Violence 2003;18:43-57.

33 Manzolli P, Nunes MA, Schmidt Ml, et al. Abuse against women, depression, and infant morbidity: a primary care cohort study in Brazil. Am J Prev Med 2012:43:188-95.

34 Holmes MR. Aggressive behavior of children exposed to intimate partner violence: an examination of maternal mental health, maternal warmth and child maltreatment. Child Abuse Neg/ 2013;37:520-30

35 Reynolds RM. Glucocorticoid excess and the developmental origins of disease: two decades of testing the hypothesis - 2012 Curt Richter Award winner. Psychoneuroendocrinology 2013;38:1-11

36 Choi J, Jeong B, Polcari A, et al. Reduced fractional anisotropy in the visual limbic pathway of young adults witnessing domestic violence in childhood. Neuroimage 2012;59:1071-9.

37 Wright RJ, Cohen RT, Cohen S. The impact of stress on the development and expression of atopy. Curr Opin Allergy Clin Immunol 2005;5:23-9.

38 Beijers R, Buitelaar JK, de Weerth C. Mechanisms underlying the effects of prenatal psychosocial stress on child outcomes: beyond the HPA axis. Eur Child Adolesc Psychiatry 2014;23:943-56.

39 Brickell K. Clouding the judgment of domestic violence law: victim blaming by institutional stakeholders in Cambodia. J Interpers Violence 2017;32:1358-78.

40 Kingdom of Cambodia. Law on the prevention of domestic violence and the protection of victims 2005 